\title{
TREND ANALYSIS OF TEMPORAL VARIATIONS IN EVI WITH RESPECT TO RAINFALL OF JAIPUR DISTRICT
}

\author{
Garima Sharma ${ }^{1}$, Shabeena Zaidi ${ }^{2}$, Rohit Goyal ${ }^{3}$ \\ ${ }^{1}$ M.Tech Student, Malaviya National Institute of Technology, Rajasthan, India \\ ${ }^{2}$ M.Tech Student, Malaviya National Institute of Technology, Rajasthan, India \\ ${ }^{3}$ Professor, Malaviya National Institute of Technology, Rajasthan, India
}

\begin{abstract}
For the protection and restoration of vegetation, it is imperative to comprehend and map current states of its distribution. Vegetation mapping and its quantification helps in understanding and correlating the factors that contribute to its spread cover over different regions. 'Jaipur city', also called Pink city is the capital of the state of Rajasthan lying in the semi-arid zone. Irregular and intermittent rainfall and drastic changes in land use and land cover types highly influence vegetation cover in the region. In order to study influence of erratic patterns of rainfall on vegetation, this study analyses the trend followed by the PostMonsoonal vegetation pattern of Jaipur with respect to the monsoonal rainfall in the years 2003 to 2010 with help of remote sensing data. Freely available remotely sensed data of Enhanced Vegetation Index (EVI) from MODIS and rainfall data from water resources department are processed here to exhibit the dependence of natural vegetation distribution in arid and semi-arid regions on rainfall. It is concluded that the EVI value rises with rise in rainfall. Coefficient of correlation value of 0.138 suggests that other factors may also be responsible for variations in EVI than rainfall. It is also concluded that MODIS EVI gives good estimation of seasonal patterns.
\end{abstract}

Key Words: Enhanced Vegetation Index (EVI), Rainfall, MODIS, Remote Sensing, Geographical Information Systems

\section{INTRODUCTION}

With the rapid global change, it has become imperative to assess the state of natural resources on earth's surface that are crucial for environment and sustainable human survival. Natural vegetation holds utmost importance to be monitored as it is the primary and basic requisite not only for meeting the food, fodder and shelter needs but also for maintaining balanced $\mathrm{CO}_{2}$ level, biodiversity, climate and environment [1]. Agriculture becomes the backbone of economy in agrarian country like India. Thus it becomes essential to analyze effect of different climatic parameters on vegetation cover. Monsoon plays a leading role influencing vegetation among factors like rainfall, land use and land cover pattern, sunlight, temperature, soil, etc. Spatial and temporal variations in rainfall directly affect phenology of vegetation along with physiographical changes of land. Thus attempts are made to develop relationship between rainfall and vegetation using remote sensing (RS) data and latest tools of Geographical Information Systems (GIS).

Remote sensing acts as an important tool in obtaining spatial and temporal data to monitor regional to global variations for various dynamics because of synoptic coverage at regular intervals [2]. According to Singhal and Goyal (2014), applications of remote sensing have fundamentally changed our thoughts and ways to manage our natural resources in general and water resources in particular [3]. Moderate Resolution Imaging Spectroradiometer (MODIS) onboard NASA's Terra and Aqua spacecraft are providing global remote sensing data products since 2000, with daily reflectance data at spatial resolutions of $250 \mathrm{~m}, 500 \mathrm{~m}$, and
$1 \mathrm{~km}$ globally with substantially improved geometric and radiometric properties corrected atmospherically and screened for clouds [4].

Vegetation Indices like Normalized Difference Vegetation Index (NDVI), Enhanced Vegetation Index (EVI) are dynamic vegetation indices provided by MODIS sensor. Remote sensing studies of vegetation normally use specific wavelengths selected to provide information about the vegetation present in the area from which the radiance data emanate [5]. EVI is an 'optimized' index designed to enhance the vegetation signal with improved sensitivity in high biomass regions and improved vegetation monitoring through a de-coupling of the canopy background signal and a reduction in atmosphere influences, thus is an enhancement on the NDVI.

\section{AREA OF STUDY}

Jaipur, the capital of Rajasthan State is situated in the eastern part having the co-ordinates $26.92^{\circ} \mathrm{N} 75.82^{\circ} \mathrm{E}$ with an average elevation of 431 metres. Banas and Banganga are the major rivers in this region as shown in Fig 1. Jaipur has a hot semi-arid climate receiving over $650 \mathrm{~mm}$ (26 in) of rainfall annually with monsoon months between June and September. During the monsoons there are frequent, heavy rains and thunderstorms [6].

Over $90 \%$ of total annual rainfall is received during monsoon. Total annual potential evapo-transpiration is $1744.7 \mathrm{~mm}$. The coefficient of variation is moderate at $32.6 \%$ indicating slightly unreliable pattern of rainfall. 
Though, Jaipur city has experienced floods in 1981, the district area is prone to drought spells as witnessed during 1984 to 1989 and 1999 to 2002 [7].
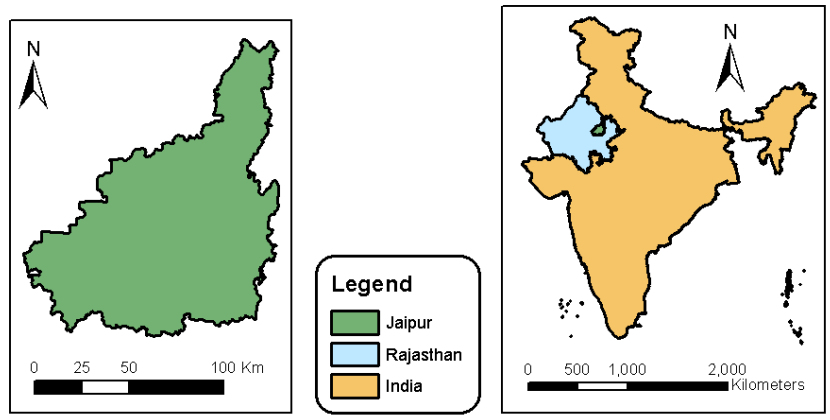

Fig -1: Jaipur District

\section{METHODOLOGY}

Vegetation trend of the region over the specified time period was studied according to the monsoonal rainfall in and around the Jaipur district. For this, methodology was divided into two parts i.e. data collection and data processing. The boundary of Jaipur district formed the base for extracting rainfall and EVI data by masking.

\subsection{Boundary of Study Area}

The study area of Jaipur district boundary was prepared using the latitudinal and longitudinal data from 'Survey of India' and Jaipur district map. The range of longitude is from $74^{\circ} 54^{\prime} 53.068^{\prime \prime} \mathrm{E}$ to $76^{\circ} 15^{\prime} 49.5899^{\prime \prime} \mathrm{E}$ and latitudinal range is from $27^{\circ} 51^{\prime} 12.86^{\prime \prime} \mathrm{N}$ at the northern most tip to $26^{\circ} 26^{\prime} 54.042$ " $N$ in South. The study area was projected in UTM zone 43.

\subsection{Data Collection}

Rainfall Data: Freely available data from 2003 to 2010 (monsoon) was collected from water resources department for several rainguage stations lying within and around the study area (Jaipur district boundary) and the total amount of rainfall was calculated. Monsoon period was taken from $15^{\text {th }}$ May to $15^{\text {th }}$ August and non-monsoon period was taken from $16^{\text {th }}$ August of the year to $14^{\text {th }}$ May of the next year.

Vegetation Data: 16 days EVI products were downloaded for the post-monsoonal season $\left(16^{\text {th }}\right.$ August to $14^{\text {th }}$ May for years 2003 to 2012). Data collected is shown in Table 1 below:

Table -1: Data Used

\begin{tabular}{|c|c|c|c|c|}
\hline Data & Source & $\begin{array}{l}\text { Satellite } \\
\text { Sensor }\end{array}$ & Year & Purpose \\
\hline $\begin{array}{l}\text { Rainfall } \\
\text { Data }\end{array}$ & $\begin{array}{l}\text { Water } \\
\text { Resource } \\
\text { Department, } \\
\text { Rajasthan }\end{array}$ & - & $\begin{array}{l}2003- \\
2010\end{array}$ & $\begin{array}{l}\text { To develop } \\
\text { Raster Map } \\
\text { of Rainfall }\end{array}$ \\
\hline $\begin{array}{l}\text { Enhanced } \\
\text { Vegetation } \\
\text { Index } \\
(\text { EVI) }\end{array}$ & $\begin{array}{l}\text { Remote } \\
\text { Sensing Data } \\
\text { using } \\
\text { LPDAAC } \\
\text { tool of NASA }\end{array}$ & MODIS & $\begin{array}{l}2003- \\
2010\end{array}$ & $\begin{array}{l}\text { To prepare } \\
\text { Vegetation } \\
\text { Raster Map }\end{array}$ \\
\hline
\end{tabular}

\subsection{Data Processing}

EVI data for all years were extracted for Jaipur district and raster maps were prepared as shown in Fig 2. Rainfall data, collected with the coordinates of raingauge stations in and around Jaipur district, as shown in Fig 3, was used to prepare point shapefile of rainfall gauges.

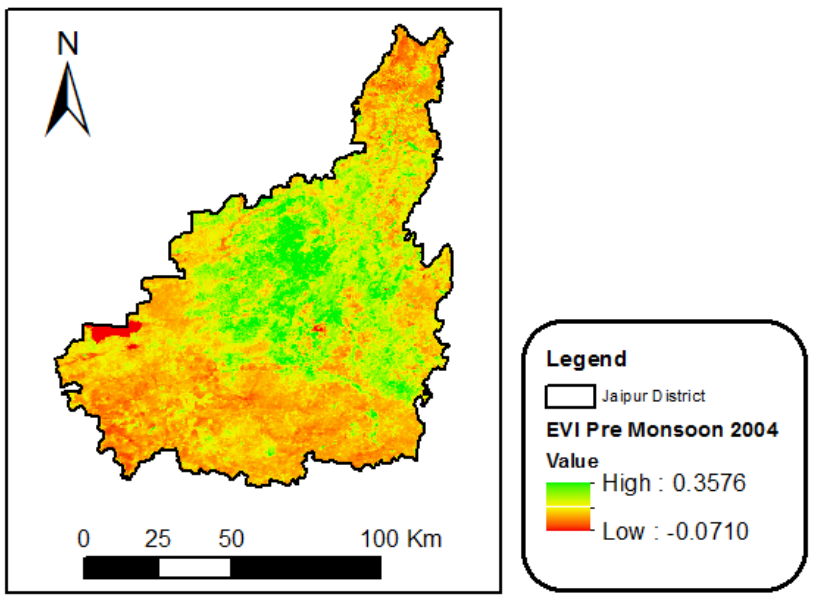

Fig -2: Extracted Image of EVI

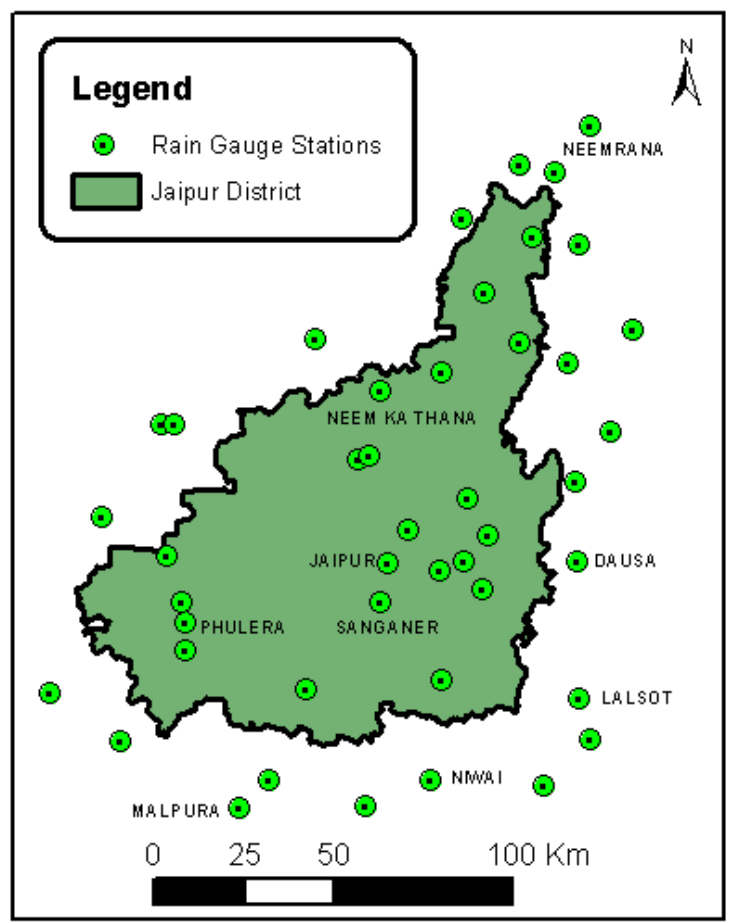

Fig -3: Raingauge Stations of Jaipur

Rainfall raster map of extracted data was prepared using natural neighbor interpolation and then extracted to Jaipur district boundary as shown in Fig 4. Rainfall data was reclassified into 9 zones, as given in Table 2, ranking them from lowest in year 2007 as $104.298 \mathrm{~mm}$ to the highest value $992.749 \mathrm{~mm}$ in year 2008. Table 2 shows the zonal statistics of EVI value falling in various zones of rainfall ranges for the years 2003, 2005 and 2010. 

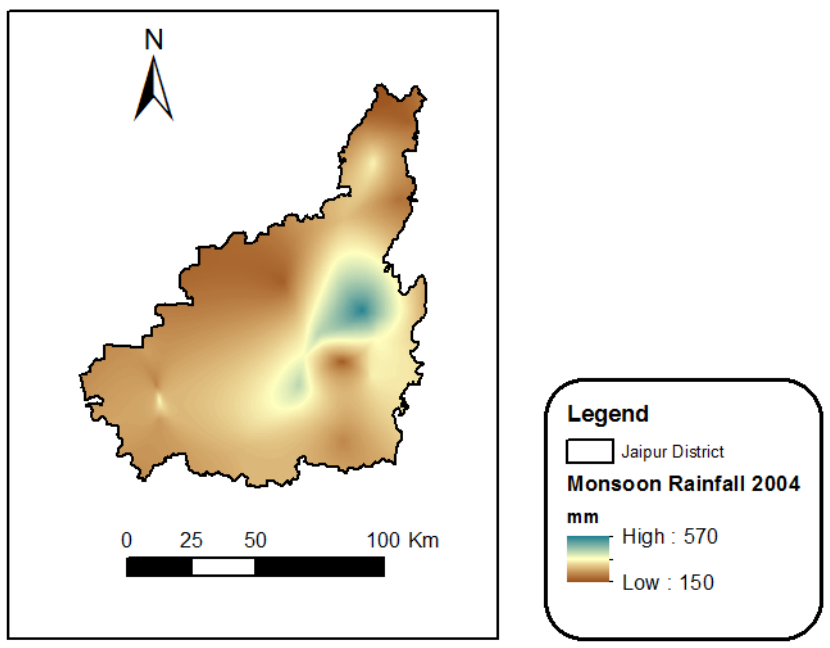

Fig -4: Extracted Rainfall for Jaipur

Table -2: Rainfall and EVI of years 2003, 2005 and 2010

\begin{tabular}{|l|c|c|c|}
\hline $\begin{array}{c}\text { Rainfall } \\
(\mathrm{mm})\end{array}$ & $\begin{array}{c}\text { EVI } \\
(2003)\end{array}$ & $\begin{array}{c}\text { EVI } \\
(2005)\end{array}$ & $\begin{array}{c}\text { EVI } \\
(2010)\end{array}$ \\
\hline $100-200$ & 0.330 & 0.395 & 0.506 \\
\hline $200-300$ & 0.437 & 0.394 & 0.454 \\
\hline $300-400$ & 0.495 & 0.367 & 0.481 \\
\hline $400-500$ & 0.430 & 0.390 & 0.458 \\
\hline $500-600$ & 0.426 & 0.399 & - \\
\hline $600-700$ & 0.461 & 0.407 & - \\
\hline $700-800$ & 0.473 & 0.445 & - \\
\hline $800-900$ & 0.512 & 0.421 & - \\
\hline $900-1000$ & - & - & - \\
\hline
\end{tabular}

\section{RESULT \& DATA ANALYSIS}

The relationships between EVI and rainfall for Jaipur district has been obtained for the years from 2003 to 2010. Graph is plotted for the above data depicting variations in vegetation with respect to rainfall as given in Fig 5 below.

As can be seen EVI values rises with rise in rainfall. There is much more variation in EVI value at lower rainfall range as compared to higher ranges. Also coefficient of correlation is only 0.138 suggesting that other factors may also be responsible for variations in EVI. Raster result images of Rainfall and EVI for the years 2003, 2005 and 2008 are shown below in Figs 6, 7, and 8. The total rainfall varies between $100 \mathrm{~mm}$ to $1000 \mathrm{~mm}$ in the years $(2003-2010)$ over the area of Jaipur district. Raster image in Fig 6 shows that there is a high rainfall in year 2003 ranging from 100 $\mathrm{mm}$ to $900 \mathrm{~mm}$, hence considerable yellow and green patches are visible in EVI image which are distributed all over the image. This reflects the effect of rainfall on vegetation.

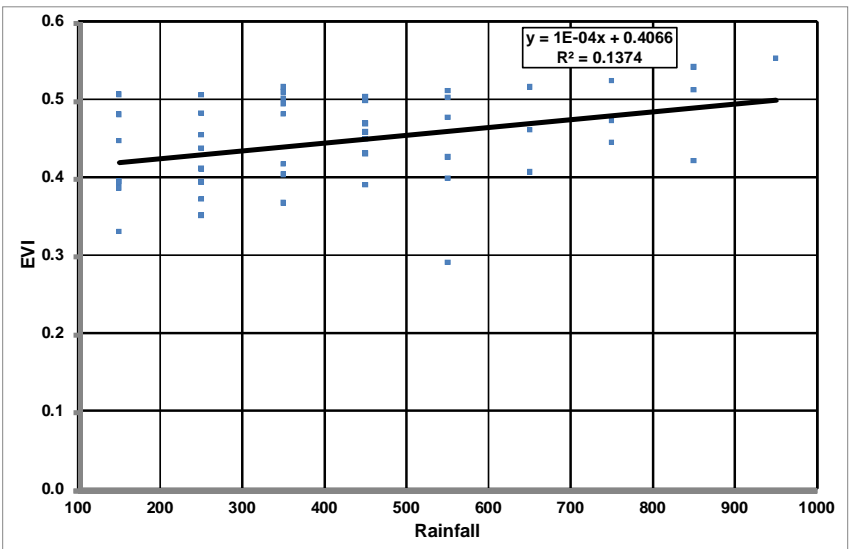

Fig -5: Rainfall Vs EVI for years 2003 to 2010

Year 2005 is shown with rainfall ranging again from 100 to $1000 \mathrm{~mm}$ in Fig 7. A large area in southern part of the district has received its rainfall within the range of 200-300 $\mathrm{mm}$ which is exhibited in the image. More green patches would be seen in northern part of district where the rainfall is also good.

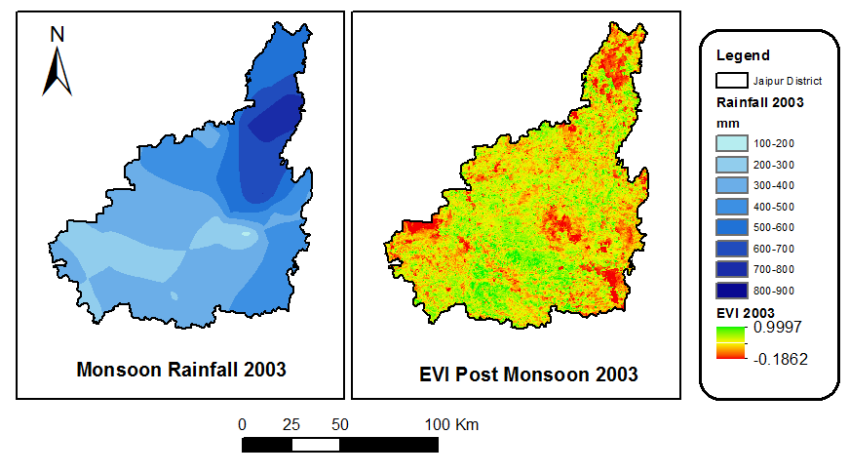

Fig -6: Rainfall Vs EVI for year 2003

In year 2008, Jaipur district has received rainfall in range of 200-1000 mm as shown in Fig 8. Large western area of the district falls in the rainfall range of 400-500 $\mathrm{mm}$. Hence, greener patches of vegetation are visible in the corresponding image of EVI. Moreover, mixed patches are also exhibited in the image which suggests that apart from rainfall there may be other factors which are equally responsible for the change in vegetation trend.
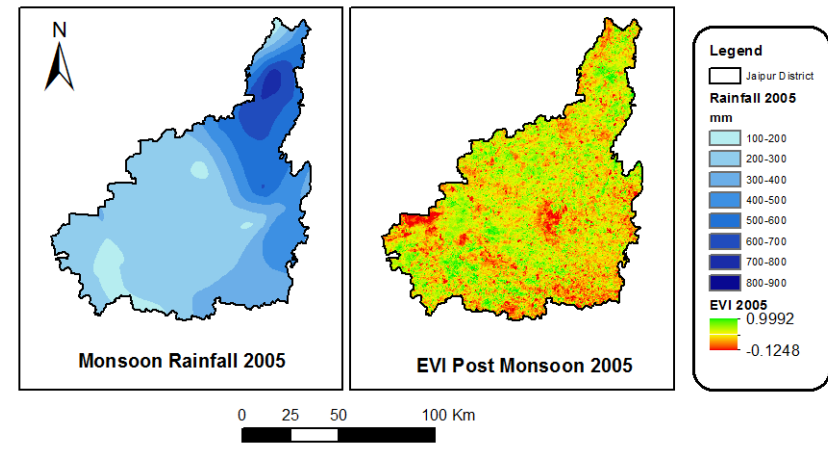

Fig -7: Rainfall Vs EVI for year 2005 


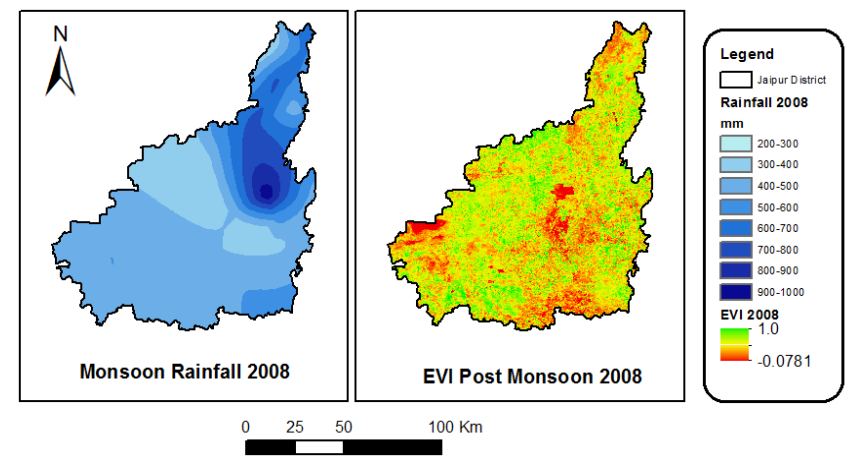

Fig -8: Rainfall Vs EVI for year 2008

Similarly, results for other years were also obtained and a varying trend was obtained with scattered patches of vegetation.

\section{CONCLUSIONS}

The trend of EVI with respect to rainfall in Jaipur district has been obtained. This shows that MODIS EVI data is very helpful in assessing changes in vegetation pattern. It is thus concluded, that though there is a considerable increase in EVI with rainfall in many areas of the district, but at some period of time in the study, this EVI data behaved tangentially and showed scattered patches irrespective of high rainfall in some regions. The normal trend in the relationship is mostly followed but the trend is not same in all the cases. This change in trend could be attributed to the climate change, due to which the pattern and time for rainfall is altered. As due to late rainfall in few years, there might be no affect or increase in EVI, because vegetation cover would have already reached the end of its growing season (5). It also indicates that rainfall is not the only factor that affects the vegetation. Vegetation of a region is also dependent on land-use and land cover pattern, soil, temperature, topographic and elevation factors. Lastly it could also be concluded that MODIS EVI gives good estimation of seasonal patterns.

\section{RECOMMENDATIONS}

The study paves the way for further analysis as the other factors apart from rainfall responsible for the change in vegetation trend such as the effect of climate change, landuse, land cover pattern, soil, temperature, topographic and elevation factors which were beyond the scope of this study, could be analysed to study the changing EVI pattern.

\section{REFERENCES}

[1]. Xiao XM, Zhang Q, Braswell B, et al. (2004) Modelling gross primary production of temperate deciduous broadleaf forest using satellite images and climate data. Remote Sens Environ 91:256-70.

[2]. Myneni, R. B., Keeling, C. D., Tucker, C. J., Asrar, G., \& Nemani, R. R., 1997. Increased plant growth in the northern high latitudes from 1981- 1991. Nature, 386, pp. 698-702.
[3]. Santra P. and Chkraborty A., Analysis of seasonal and annual change of vegetation in the Indian Thar desert using MODIS data. ISPRS Archives XXXVIII- 8/W20 175-178.

[4]. Singhal V, Goyal R (2014) Groundwater model to predict the impact due to textile units at Pali. Arab J. Geosci 7(12):5185-5192

[5]. Tucker, C. J. and Sellers, P. J.(1986). Satellite remote sensing of primary production. Int. J. Remote Sensing. 7. 1395-1416.

[6]. Karabulut M. (2003). An examination of relationships between vegetation and rainfall using maximum value composite AVHRR-NDVI data. Turk J Bot 27. 93-101.

[7]. Chandrasekar K., Sesha M. V. R., Jeyaseelan A. T., Dwivedi R. S. and Roy P.S. (2006). Vegetation response to rainfall as monitored by NOAA-AVHRR. Current Science. 91(12, 25). 1626-1633.

[8]. Ground water scenario, Jaipur district. (2007). Central ground water board, Ministry of water resources.

[9]. Enkay Enviro Services. (2011). EIA report on Amity University. Doc: - EES/AU/002/127-EC/Infra/2011/291.

\section{BIOGRAPHIES}

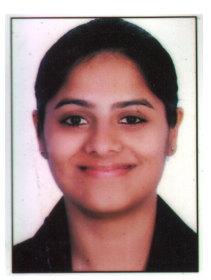

Garima Sharma has done M.Tech. in Environmental Engineering from MNIT, Jaipur. She is pursuing her $\mathrm{PhD}$ from Indian Maritime University. Her research interests are Environment, Mangroves, RS \& GIS and Oceanography.

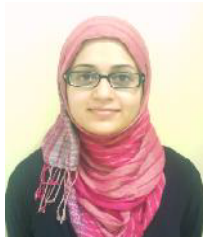

Shabeena Zaidi has done M.Tech. in Environmental Engineering from MNIT Jaipur. She has worked as Environmental Engineer in a firm. Her research interests are sustainable environmental research, RS \& GIS, waste management and recycling.

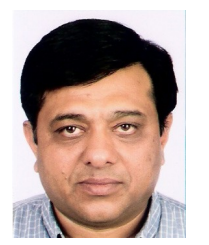

Prof. Rohit Goyal is working as Professor, Civil Engg. \& Dean Planning \& Development at MNIT Jaipur. His research interests are water resources, groundwater hydrology, RS \& GIS. 